\title{
PREDICTING DRIVING PERFORMANCE IN OLDER ADULTS WITH THE USEFUL FIELD OF VIEW TEST: A META-ANALYSIS
}

\author{
Karlene K. Ball, Olivio J. Clay, Virginia G. Wadley, David L. Roth \\ Center for Translational Research on Aging and Mobility \\ University of Alabama at Birmingham \\ Birmingham, Alabama, USA \\ E-mail: kball@uab.edu \\ Jerri D. Edwards \\ University of Alabama in Huntsville \\ Huntsville, Alabama, USA \\ Daniel L. Roenker \\ Western Kentucky University \\ Bowling Green, Kentucky, USA
}

\begin{abstract}
Summary: This investigation examines the Useful Field of View (specifically the $\mathrm{UFOV}^{\circledR}$ test), as a predictor of objective measures of driving performance. PubMed and PsycInfo databases were searched to retrieve eight independent studies reporting bivariate relationships between the $\mathrm{UFOV}^{\circledR}$ test and driving measures (driving simulator performance, state-recorded crashes, and on-road driving). Cumulative meta-analysis techniques were used to examine the predictive utility of the test, to determine whether the effect size was stable across studies, and to assess whether a sufficient number of studies have been conducted to conclude that the test is an effective predictor of driving competence. Results showed that the study samples could have been drawn from the same population. The weighted mean effect size across all studies revealed a large effect, Cohen's $\mathrm{d}=0.945$, with poorer $\mathrm{UFOV}^{\circledR}$ test performance associated with negative driving outcomes. This relationship was robust across multiple indices of driving performance and several research laboratories. A concrete measure of sufficiency revealed that an additional 513 studies averaging a null result must be conducted to bring the $\mathrm{p}$-value for the cumulative effect size to greater than .05 . This convergence of evidence across different points in time and different research teams confirms the importance of the $\mathrm{UFOV}^{\circledR}$ assessment as a valid and reliable index of driving performance and safety. Corroborating this finding, a recent large field study in Maryland has further established the $\mathrm{UFOV}^{\circledR}$ test as a useful screening instrument to identify at-risk older drivers. Taken together, these findings could have far-reaching implications for public policy.
\end{abstract}

\section{INTRODUCTION}

During a routine drive on any highway, individuals of all ages clearly demonstrate a wide range of driving ability. Individual differences in driving ability are reflected in crash statistics and as a result, highway safety researchers have sought to determine the characteristics that make some drivers safer than others. Visual information processing skills have a great deal of face validity for predicting driving competence in that they require adequate visual sensory function as well as the ability to respond quickly and appropriately to more complex information. One such skill is 
visual attention, and several studies from the early 1970's suggested that impaired visual attention was linked to crash involvement (Kahneman \& Ben-Ishai, 1973; Mihal \& Barrett, 1977). However, these findings were not further explored until the relatively recent body of work (Ball \& Owsley, 1991; Ball \& Owsley, 1993; Ball, Owsley, et al., 1993; Owsley, Ball, et al., 1998) that examined a higher order visual/cognitive process that has been coined the Useful Field of View (Ball, Beard et al., 1988).

The purpose of this investigation is to examine the ability of the UFOV ${ }^{\circledR}$ assessment to identify older adults at risk for adverse driving outcomes. Studies that used state-reported crashes, simulated driving performance, or on-road driving performance as outcome measures were included, whereas those that involved self-reported automobile crashes as the only measure of driving performance were omitted due to possible reporting biases for older adults. Cumulative meta-analysis was used to combine the results. It was hypothesized that (1) poorer $\mathrm{UFOV}^{\circledR}$ performance would be associated with poorer driving performance among older adults, (2) the magnitude of this relationship would remain relatively stable across time, and (3) existing studies would provide sufficient evidence for the strength and durability of this relationship.

\section{METHODS}

\section{Identification of relevant studies}

Relevant studies were identified by searching the PsycINFO and PubMed databases for articles published from January 1, 1985 through October 15, 2003. The keywords used to search the PsycINFO databases included "UFOV," which retrieved 12 articles and "Useful Field of View," which retrieved 30 articles. A search of the PubMed database using the keyword "UFOV" resulted in 15 citations. Using the terms "Useful Field of View" as the search criterion resulted in 372 citations. The retrieval of this large number of citations led researchers to subdivide the PubMed search into two more specific inquiries. "Useful Field of View" was combined with "driving" and "crashes" resulting in 25 and 10 citations, respectively. Criteria for studies to be included in the meta-analysis were: (a) a sample of adults age 55 and older, (b) no two studies could be based on the same sample, (c) the bivariate association between the UFOV ${ }^{\circledR}$ test and driving performance without co-varying for the effects of any other measures must be available, (d) the measure of driving performance must be retrospective or concurrent with the UFOV ${ }^{\circledR}$ assessment, and (e) the measure of driving performance must be objective rather than self-report. If more than one manuscript was found that included data based on the same protocol, only a single manuscript that reported the direct, unadjusted relationship between $\mathrm{UFOV}^{\circledR}$ performance and driving performance using the entire sample was selected.

\section{Analyses}

Cumulative Meta-Analysis. A cumulative meta-analysis was performed to examine the strength of the relationship between $\mathrm{UFOV}^{\circledR}$ performance and driving ability in older adults using the BASIC meta-analysis software (Mullen, 1989). Each study was added to the analysis individually and a new meta-analysis procedure was performed at each wave beginning with the oldest and concluding with the most recent publication. Next, the effect size at each step of the combination of studies was quantified in terms of a simple correlation (r), and Fisher's $\mathrm{r}$ to $z$ ' transformation was applied to this correlation $\left(z^{\prime}=.5[\ln (1+r)-\ln (1-r)]\right)$. Finally, $95 \%$ 
confidence intervals (CI), 95\% CI $=z^{\prime} \pm 1.96[1 / \operatorname{sqr}(n-3)]$, were calculated for each $z$ ' effect size.

\section{RESULTS}

Eight unique studies met criteria for inclusion in the cumulative meta-analysis. These studies are described with respect to the population from which the sample was drawn, the test statistic reported, sample size, and the sample effect size (see below). For each of the studies, an asterisk denotes data collected by the authors, 2 asterisks denotes data collected independently, with collaboration by one of more of the authors, and "^" indicates data collected and analyzed independently.

\begin{tabular}{|c|c|c|c|c|c|c|c|}
\hline Study & Driving Outcome & Population & Statistic & df & $\mathbf{N}$ & Weight & $\begin{array}{l}\text { Sample } \\
\text { Effect } \\
\left.\text { Size ( } z^{\prime}\right)\end{array}$ \\
\hline $\begin{array}{l}* \text { Owsley } \\
1991\end{array}$ & $\begin{array}{l}\text { Crashes in last } 5 \\
\text { years (state } \\
\text { records) }\end{array}$ & $\begin{array}{l}\text { Active licensed drivers } \\
57-83\end{array}$ & $\mathrm{r}=.36$ & 51 & 53 & 53 & .3769 \\
\hline *Ball, 1993 & $\begin{array}{l}\text { At -fault crashes } \\
\text { (state records) }\end{array}$ & $\begin{array}{l}\text { Active licensed drivers } \\
56-90\end{array}$ & $\mathrm{r}=0.52$ & 292 & 294 & 294 & .5763 \\
\hline $\begin{array}{l}\text { ^Wood, } \\
1995\end{array}$ & $\begin{array}{l}\text { Driving } \\
\text { performance on a } \\
\text { closed road circuit }\end{array}$ & $\begin{array}{l}\text { Current licensed drivers } \\
60-74 \text { in good ocular } \\
\text { health }\end{array}$ & $\mathrm{r}=0.55$ & 8 & 10 & 10 & .6181 \\
\hline $\begin{array}{l}\text { ^Cushman, } \\
1996\end{array}$ & $\begin{array}{l}\text { On-road driving } \\
\text { performance }\end{array}$ & $\begin{array}{l}\text { Current licensed drivers } \\
55+, 91 \text { volunteers, } 32 \\
\text { with early AD }\end{array}$ & $\chi^{2}=46.0$ & 1 & 123 & 123 & .7114 \\
\hline $\begin{array}{l}\text { **Rizzo, } \\
1997\end{array}$ & $\begin{array}{l}\text { Crashes in driving } \\
\text { simulator }\end{array}$ & $\begin{array}{l}\text { Current licensed } \\
\text { drivers, } 21 \text { with } \mathrm{AD} \text { and } \\
18 \text { controls }\end{array}$ & $\chi^{2}=10.925$ & 1 & 39 & 39 & .5891 \\
\hline $\begin{array}{l}* * \text { Duchek } \\
1998\end{array}$ & $\begin{array}{l}\text { Driving } \\
\text { performance (on- } \\
\text { road test) }\end{array}$ & $\begin{array}{l}\text { Current licensed drivers } \\
\text { (healthy controls, very } \\
\text { mild AD, mild AD) }\end{array}$ & $r=-.56$ & 53 & 55 & 55 & .6328 \\
\hline $\begin{array}{l}* * \text { Myers } \\
2000\end{array}$ & $\begin{array}{l}\text { Driving } \\
\text { performance } \\
\text { (on-road test) }\end{array}$ & $\begin{array}{l}\text { Patients referred to } \\
\text { Bryn Mawr Rehab } \\
\text { Adapted Driving } \\
\text { Program (61-91) }\end{array}$ & $\chi^{2}=23.67$ & 1 & 43 & 43 & .9548 \\
\hline $\begin{array}{l}\text { *Roenker, } \\
2003\end{array}$ & $\begin{array}{l}\text { Driving } \\
\text { performance } \\
\text { (simulator) }\end{array}$ & $\begin{array}{l}\text { Older drivers } 55+ \\
\text { UFOV }^{\circledR} \text { reduction of at } \\
\text { least } 30 \% \text {. }\end{array}$ & $\mathrm{r}=0.422$ & 93 & 95 & 95 & .4477 \\
\hline
\end{tabular}

These investigations had a combined sample size of 712 adult drivers over the age of 55 . In an attempt to determine whether the studies could be thought of as coming from the same population, the within-group homogeneity of the effect sizes was tested (Hedges \& Olkin, 1985). The value for the $\mathrm{Q}$ statistic was not statistically significant, $Q(7)=11.29, \mathrm{p}$ (one-tailed) $=.13$, indicating that the samples can be considered homogeneous. Therefore, further combination of the group effect sizes is warranted (Durlak, 1995). 
The final weighted, cumulative effect size after adding all eight studies into the analysis was $z^{\prime}=.60$. The $95 \%$ confidence interval for this effect does not contain 0 , signifying that the effect is significantly greater than 0 . The combined Fisher's $z$ ' of .60 is equivalent to an average correlation of .535. This correlation was then converted to Cohen's $d$, which represents the difference between means in standard deviation units. The effect size yielded by combining these eight studies, $d=0.945$, was well above Cohen's threshold for a large effect $(\mathrm{d}=0.8)$ even after the correction was applied. Additionally, the eight studies were subdivided into 3 categories: studies conducted by individuals with financial interests in the UFOV ${ }^{\circledR}$ test (Ball et al., 1993; Owsley et al., 1991; Roenker et al., 2003), studies in which data were collected and analyzed in independent laboratories that subsequently requested collaboration of UFOV ${ }^{\circledR}$ creators during the preparation of manuscripts (Duchek et al., 1998; Myers et al., 2000; Rizzo et al., 1997) and studies in which the data were collected, analyzed, and reported independently (Wood \& Troutbeck, 1995; Cushman, 1996). The mean effect sizes for these three subgroups (Cohen's $d$ ) were $0.831,1.133$, and 1.109 , respectively.

A measure of sufficiency was examined by using the BASIC meta-analysis software to calculate the failsafe number (Cooper, 1979). This unweighted procedure revealed that an additional 513 studies that averaged a null result must be conducted to bring the p-value for the cumulative effect size to be greater than .05. In other words, many null findings would be necessary in order to negate the result of this meta-analysis. Finally, the mean effect size at each wave varied only slightly, suggesting stability across studies conducted at different points in time by different research teams.

\section{DISCUSSION}

The data present a relatively clear picture: poorer $\mathrm{UFOV}^{\circledR}$ test performance is associated with poor driving performance in older adults. The effect size obtained when the UFOV ${ }^{\circledR}$ assessment was correlated with objective driving performance is large compared to standard assessments of visual acuity, other visual sensory functions, and various cognitive domains ${ }^{14,36}$ (Owsley et al., 1991; Goode et al., 1998). This highlights the utility of higher-order visual-cognitive processes in predicting driving performance. The consistency of the relationship between $\mathrm{UFOV}^{\circledR}$ and driving has been discussed in several related review articles (e.g., Ball \& Owsley, 2000); the current meta-analysis serves as quantitative confirmation of this relationship. With regard to the relationship between $\mathrm{UFOV}^{\circledR}$ test performance and driving, it is noteworthy that the relationship is robust across multiple indices of driving performance and several research laboratories. In this review, we examined studies using as performance criteria state-recorded crash records, on-road driving, and driving simulator performance. The relationship between $\mathrm{UFOV}^{\circledR}$ performance and driving competence was strong for all outcome measures. This convergence of evidence across numerous studies using different methodologies strongly suggests that the $\mathrm{UFOV}^{\circledR}$ assessment is a valid and reliable index of driving performance and safety. Additionally, the selection of only one effect per protocol (i.e., only one study using a given sample) diminishes the potential to overweight studies with positive findings.

Other reports have examined the relationship between measures of attention/concentration and driving performance. Reger and associates performed a meta-analysis that examined UFOV ${ }^{\circledR}$, Trails A, Digit Span, Digit Symbol and other measures to show their ability to predict driving performance (Reger et al., 2004). Their analysis was restricted to studies of participants with 
dementia, and studies included in their analysis included less objective measures of driving performance such as tests of driving knowledge and caregivers' reports of driving ability. If more than one measure of attention and concentration was reported in the same study, Reger and associates combined the effects and included them in their final results. The selection of only demented patients, and the combination of $\mathrm{UFOV}^{\circledR}$ with less effective predictors of driving performance may account for the smaller uncorrected mean effect sizes found in their investigation, $\mathrm{r}=.48$ for on-road tests and $\mathrm{r}=.35$ for non-road tests.

The strong association between $\mathrm{UFOV}^{\circledR}$ performance and retrospective crashes (Ball et al., 1993) led to a supplemental investigation of the same age- and crash-stratified sample of 294 older drivers to evaluate $\mathrm{UFOV}^{\circledR}$ as a predictor of prospective crash involvement (Owsley et al., 1998). Crash records were collected for the three years following the single clinic visit completed by each participant. Visual acuity, contrast sensitivity, stereoacuity, disability glare, visual field sensitivity, and a $40 \%$ reduction in $\mathrm{UFOV}^{\circledR}$ were each examined as potential predictors of crash rate, which was measured in terms of crashes per million person-miles of travel. UFOV ${ }^{\circledR}$ was a significant predictor of crash rate from bivariate analysis, and when adjusted for age, sex, race, mental status, and chronic medical conditions, individuals with a $40 \%$ reduction in UFOV ${ }^{\circledR}$ were 2.2 times more likely to be involved in a crash. This investigation specifically evaluated the predictive utility of the UFOV ${ }^{\circledR}$ and does not negate the potential importance of other measures of higher cognitive processing or visual information processing.

The evidence of a relationship between $\mathrm{UFOV}^{\circledR}$ test performance and driving performance has far-reaching implications for public policy. If a screening battery incorporating the UFOV ${ }^{\circledR}$ assessment were widely adopted by state Departments of Motor Vehicles, then drivers with identified risk could potentially be referred for appropriate interventions to restore safe mobility. There is now a growing body of literature indicating that visual processing speed can be improved through training, and that such training results in improved driving safety and other indices of mobility (Roenker et al., 2003; Ball et al., 2002).

An initial field study has been completed that evaluated the UFOV ${ }^{\circledR}$ and other tests as a potential screening battery. A population-based study recently assessed older adults coming in to renew their driver's licenses in three Motor Vehicle Administration (MVA) field site offices in the state of Maryland. A total of 2,114 elders agreed to assist in the evaluation of a series of screening measures. The screening battery was designed to be brief; therefore, only subtest 2 of the $\mathrm{UFOV}^{\circledR}$ test was included (among the three subtests of the $\mathrm{UFOV}^{\circledR}$, subtest 2 has been found to have the highest correlation with at-fault crashes). An analysis of at-fault crashes in the 2.5 years following assessment (adjusted for driving exposure) showed that individuals with poor $\mathrm{UFOV}^{\circledR}$ performance were over two times as likely to be involved in an at-fault crash (Ball \& Edwards, 2001). These prospective results, which are based on a primarily unimpaired sample of licensed drivers, reinforce the retrospective and concurrent results presented in this metaanalysis. Results are consistent with the position that poor $\mathrm{UFOV}^{\circledR}$ performance, associated with poor visual sensory function, $\mathrm{AD}$, stroke, or simply increasing age, is a significant indicator of crash risk. Additional prospective, longitudinal studies are needed to investigate potential differences in the predictive power of the $\mathrm{UFOV}^{\circledR}$ in samples with early dementia, medical impairments such as stroke, and samples of community dwelling older adults. 
In summary, the current cumulative meta-analysis revealed that a sufficient number of studies have been conducted to conclusively demonstrate that the UFOV ${ }^{\circledR}$ test is a valid indicator of retrospective and concurrent driving performance in older adults. Although performance on the $\mathrm{UFOV}^{\circledR}$ does not provide information in terms of what the underlying causes of visual information processing failures might be, it does represents a final common pathway of higher visual and cognitive impairment. Furthermore, the effectiveness of the UFOV ${ }^{\circledR}$ measure as a predictor of incident crashes and as a screen for detecting at-risk older drivers corroborates our results. The remaining step is to apply this knowledge base in a reasonable and concise manner as a means of increasing the viability and safety of older adults who continue to drive.

\section{ACKNOWLEDGMENTS}

This research program is funded by NIA Grants 5P30 AG022838 and 5R37 AG05739 (Edward R. Roybal Center for Research on Applied Gerontology). Drs. Ball and Roenker own stock in Visual Awareness Inc., which owns the patent for UFOV ${ }^{\circledR}$ testing and training software.

\section{REFERENCES}

Ball, K.K., Beard, B.L., Roenker, D.L., Miller, R.L., \& Griggs, D.S. (1988). Age and visual search: Expanding the useful field of view. Journal of Optical Society of America A, (5), 2210-2219.

Ball, K.K., Berch, D.B., Helmers, K.F., Jobe, J.B., Leveck, M.D., Marsiske, M, et al.(2002). Effects of cognitive training interventions with older adults: A randomized controlled trial. Journal of the American Medical Association, 288, 2271-2281.

Ball, K.K., \& Edwards, J.D. (2001). Relationship of the brief battery to state crash records. The Gerontologist, 41, (Special Issue 1), 179.

Ball, K.K., \& Owsley, C. (1991). Identifying correlates of accident involvement for the older driver. Human Factors, 33, 583-595.

Ball, K.K., \& Owsley C. (1993). The useful field of view test: A new technique for evaluating age-related declines in visual function. Journal of the American Optometric Association ,64, 71-79.

Ball, K., \& Owsley C. (2000). Increasing mobility and reducing accidents of older drivers. In K.W. Schaie, \& M. Pietrucha (Eds.), Mobility and Transportation in the Elderly (pp. 213250). New York: Springer.

Ball, K.K., Owsley, C., Sloane, M.E., Roenker, D.L., \& Bruni, J.R. (1993). Visual attention problems as a predictor of vehicle crashes in older drivers. Investigative Ophthalmology and Visual Science, 34, 3110-3123.

Cohen J. (1988). Statistical power analysis for the behavioral sciences (2nd ed.). Hillsdale, NJ: Lawrence Earlbaum Associates.

Cooper, H.M.(1979). Statistically combining independent studies: A meta-analysis of sex differences in conformity research. Journal of Personal and Social Psychology, 37, 131-146.

Cushman, L.A. (1996). Cognitive capacity and concurrent driving performance in older drivers. IATSS Research, 20, 38-45. 
Duchek, J.M., Hunt, L., Ball, K.K., Buckles, V., \& Morris, J.C. (1998). Attention and driving performance in Alzheimer's disease. The Journals of Gerontology B-Psychological Sciences and Social Sciences, 53, 130-141.

Durlak, J.A. Understanding meta-analysis. (1995). In Grimm, L.G., \& Yarnold, P.R., (Eds.) Reading and understanding multivariate statistics (pp. 319-352). Washington, DC: American Psychological Association.

Goode, K.T., Ball, K.K., Sloane, M.E., Roenker, D.L., Roth, D.L., Myers, R.S., \& Owsley, C. (1998). Useful field of view and other neurocognitive indicators of crash risk in older adults. Journal of Clinical Psychology in Medical Settings, 5, 425-440.

Hedges, L.V., \& Olkin, I. (1995). Statistical methods for meta-analysis. San Diego, CA: Academic Press.

Kahneman, D., \& Ben-Ishai R. (1993). Relation of a test of attention to road accidents. Journal of Applied Psychology, 58, 113-115.

Mihal, W. L., \& Barrett, G.V. (1976). Individual differences in perceptual information processing and their relation to automobile accident involvement. Journal of Applied Psychology, 61, 229-233.

Mullen, B. (1989). Advanced BASIC meta-analysis. Hillsdale, NJ: Lawrence Erlbaum.

Mullen, B., Muellerleile, P., \& Bryant, B. (2001). Cumulative meta-analysis: A consideration of indicators of sufficiency and stability. Journal of Personality and Social Psychology B, 27, 1450-1462.

Myers, R.S., Ball, K.K., Kalina, T.D., Roth, D.L., \& Goode K.T. (2000). The relationship of useful field of view and other screening instruments to on-road driving performance. Perceptual and Motor Skills, 91, 279-290.

Owsley, C., Ball, K.K., McGwin, G., Sloane, M.E., Roenker, D.L., White, M., \& Overley, E.T. (1998). Visual processing impairment and risk of motor vehicle crash among older adults. Journalof the American Medical Association, 279, 1083-1088.

Owsley, C., Ball, K.K., Sloane, M.E., Roenker, D.L., \& Bruni, J.R. (1991). Visual/cognitive correlates of vehicle accidents in older drivers. Psychology and Aging, 6, 403-415.

Reger, M.A., Welsh, R.K., Watson, G.S., Cholerton, B., Baker, L.D., \& Craft, S. (2004). The relationship between neuropsychological functioning and driving ability in dementia: A metaanalysis. Neuropsychology, 18(1), 85-93.

Rizzo, M., Reinach, S., McGehee, D., \& Dawson , J. (1997). Simulated car crashes and crash predictors in drivers with Alzheimer disease. Archives of Neurology, 54, 545-551.

Roenker, D.L., Cissell, G., Ball, K.K., Wadley, V.G., \& Edwards, J.D. (2003). Speed of processing and driving simulator training result in improved driving performance. Human Factors, 45, 218-233.

Wood, J.M., \& Troutbeck, R. (1995). Elderly drivers and simulated visual impairment. Optometry and Vision Science, 72, 115-24. 